\title{
Irrigation frequency and substrate volume effects in the growth and yield of tomato plants under greenhouse conditions
}

\author{
Regina Célia de Matos Pires ${ }^{1 *}$, Pedro Roberto Furlani ${ }^{2}$, Rafael Vasconcelos Ribeiro ${ }^{1}$, Décio \\ Bodine Junior ${ }^{1}$, Emílio Sakai $^{1}$, André Luiz Lourenção ${ }^{3}$, André Torre Neto ${ }^{4}$ \\ ${ }^{1}$ IAC - Centro de Pesquisa e Desenvolvimento de Ecofisiologia e Biofísica, C.P. 28 - 13012-970 - Campinas, SP - \\ Brasil. \\ ${ }_{3}^{2} I A C-$ Centro de Pesquisa e Desenvolvimento de Solos e Recursos Ambientais. \\ ${ }^{3}$ IAC - Centro de Pesquisa e Desenvolvimento de Fitossanidade. \\ ${ }^{4}$ Embrapa Instrumentação Agropecuária, C.P. 741 - 13560-970 - São Carlos, SP - Brasil. \\ *Corresponding author <rcmpires@iac.sp.gov.br> \\ Edited by: Edmilson José Ambrosano
}

\begin{abstract}
Tomato cropping (Solanum lycopersicum L.) under protected cultivation using substrates and drip fertigation has improved sustainable production systems especially fruit quality and plant health. However, little is known for tomato plants when considering the interaction between substrate volume and irrigation frequency. The aim of this study was to evaluate the effects of coconut (Cocos nucifera L.) fiber substrate volumes and drip irrigation frequencies on the vegetative growth and fruit yield of tomato plants under greenhouse conditions. The experimental design consisted of randomized blocks arranged in a $3 \times 2$ factorial with four replicates. Treatments consisted of three substrate volumes $(5.0 ; 7.5$ and $10.0 \mathrm{~L}$ per plant) and two irrigation frequencies (once and five times per day). Leaf area index tended to increase in plants grown with the largest substrate volume $(10 \mathrm{~L})$. Although substrate volumes affected shoot dry matter, no effects on tomato yield and its components were observed. However, plants grown with $5 \mathrm{~L}$ of substrate and irrigated once a day produced a greater number of non-marketable fruit due to the higher incidence of calcium deficiency symptoms (blossom end rot). When plants were grown in $5 \mathrm{~L}$ or $7.5 \mathrm{~L}$ of substrate volume, high irrigation frequency favored the vegetative growth, stomatal conductance, $\mathrm{CO}_{2}$ assimilation and transpiration and fruit yield. Fruit yield and healthy fruits were favored by high irrigation frequency and did not depend on the substrate volume.

Keywords: Solanum lycopersicum L., fertigation, gas exchange, trickle irrigation, water management
\end{abstract}

\section{Introduction}

Tomato plants (Solanum lycopersicum L.) are susceptible to pests and diseases, and plant health is affected by water and nutrient supply (Harmanto et al., 2005). Intensive soil cultivation in greenhouses causes cropping failure related to soil salinity and plant health. For this reason, advanced greenhouse cultivation has changed the substrate for growth by using inert substrates instead of soil (Sezen et al., 2010) and supplying nutrients by fertigation (Fandi et al., 2008). Appropriate substrate and rational water and nutrient supply by drip fertigation has benefited the yield and quality of tomatoes (Harmanto et al., 2005; Mahajan and Singh, 2006; Ismail et al., 2008; Pires et al., 2009) and contributed to environmental preservation (Berjón et al., 2005).

Several authors have compared the efficacy of substrates for tomato production (Çelikel, 1999; Carrijo et al., 2004; Chen Lopez et al., 2008; Sampaio et al., 2008; Sezen et al., 2010). The use of coconut (Cocos nucifera L.) fiber as substrate for greenhouse tomatoes has provided acceptable plant development and high fruit yield (Carrijo et al., 2004; Pires et al., 2009). However, the use of substrates increases production costs so that the substrate volume must be optimized to obtain maximum economic production. Castilla and Montalvo (2005), Sezen et al. (2006) and Pires et al. (2009) pointed out the importance of a correct irrigation frequency, especially when using substrates. In fact, the water retention characteristics of a growth medium, soil and other substrates interfere with plant physiology, growth and fruit yield (Sezen et al., 2006). As a result, the benefits of high frequency irrigation systems will depend on the substrate volume and the balance between aeration and water holding capacity. The aim of this study was to evaluate the effects of coconut fiber substrate volumes and drip irrigation frequencies on the vegetative growth and fruit yield of tomato plants under greenhouse conditions.

\section{Materials and Methods}

The experiment was carried out from May to October 2005 , in a $350 \mathrm{~m}^{2}(7 \times 50 \mathrm{~m})$ greenhouse, in Campinas, state of São Paulo, Brazil (22 ${ }^{\circ} 54^{\prime}$ S, $47^{\circ} 05^{\prime}$ W and 669 m of altitude). The greenhouse has a bow-roof shed design structure with $30 \%$ shading screen in the lateral walls, covered with $100 \mu \mathrm{m}$ thick transparent polyethylene film) and oriented $245^{\circ} 75^{\prime}$ in relation to the magnetic North.

Seedlings of Ikram tomato hybrid (a marketable clustertype) 36-day old were transplanted to $14 \mathrm{~L}$ plastic pots $(0.257$ $\mathrm{m}$ diameter and $0.270 \mathrm{~m}$ height) in May 24, 2005. During the experimental period, plants were tutored, sprouts, old leaves and weeds were removed and pests and diseases were controlled with pesticide sprayings according to recommended procedures. The sprouts were removed such that one stalk per plant was left and vertically tutored. The experimental design consisted of randomized blocks arranged 
in a $3 \times 2$ factorial with four replicates. Each plot consisted of 24 plants (two rows of 12 plants), spaced $0.6 \mathrm{~m}$ in the row and $0.8 \mathrm{~m}$ between rows (approximately two plants per $\left.\mathrm{m}^{2}\right)$.

Coconut fiber was used as substrate, with varying volumes: 5, 7.5 and $10 \mathrm{~L}$ per plant. The physical characteristics of the substrate are: $96 \%$ of total porosity, $45 \%$ of air-filled porosity, $20 \%$ of readily available water and water retention capacity of $0.538 \mathrm{~L} \mathrm{~L}^{-1}$ (Sánches, 1999). Drip irrigation was applied using one emitter per plant, which consisted of a pressure compensating dripper with anti-drain functionality, allowing a $3.2 \mathrm{~L} \mathrm{~h}^{-1}$ of discharge flow rate. Water was applied by on line drippers, using a micro-tube and stake per plant. The irrigation frequencies consisted of one application per day (at 7h00) and five applications per day (at 8h00, 10h00, 12h00, 14h00, and 16h00)

Before beginning the experiment, substrates were irrigated until field capacity and afterwards water consumption was monitored. The irrigation volume was estimated by the water consumption in the previous day, by means of the mass difference registered in lysimeters (two per treatment) and considering the volume difference between the water applied and the collected percolate volume. The lysimeters consisted of two pots of plants over a $50 \mathrm{~kg}$ capacity load balance with precision of $0.01 \mathrm{~kg}$ and a percolate collector. In all plots, seedlings received equal irrigation frequency up to 8 days after transplanting (DAT). Afterwards, two irrigation frequencies were applied to the plots, which consisted of fertigations. Daily irrigation was provided according to plant water consumption, which varied for each treatment. The nutrient solution formula was based on the Sonneveld and Straver (1994) recommendation, with adaptations according to the plant demand evaluated by visual deficiency symptoms and analysis of leaves and pot percolates. The formulations of nutrient solutions used in the fertigations are presented in Table 1.

Concentrated nutrient solutions were prepared in two tanks (A and B) to prevent chemical precipitation. The fertigation solutions for each phase of tomato plant development were prepared as follows: $12.5 \mathrm{~L}$ of each one of the $\mathrm{A}$ and $\mathrm{B}$ concentrated solutions were added to a 1,000 L tank containing almost $900 \mathrm{~L}$ of water; the volume was homogenized and the volume completed to 1,000 L with water. During the vegetative growth, the concentration of macronutrients (mg L ${ }^{-1}$ ) were: $\mathrm{N}_{-} \mathrm{NO}_{3}(167), \mathrm{N}^{-N_{4}}(30), \mathrm{P}(52)$, $\mathrm{K}$ (164), $\mathrm{Ca}(143), \mathrm{Mg}$ (36) and $\mathrm{S}$ (48); and during the reproductive phase, the concentrations ( $\mathrm{mg} \mathrm{L}^{-1}$ ) were: $\mathrm{N}^{-N}{ }_{3}(167)$, $\mathrm{N}_{-\mathrm{NH}_{4}}$ (19), P (59), K (268), Ca (143), Mg (36) and S (74). For the micronutrients, the same concentrations were applied throughout plant cycle, as follows $\left(\mathrm{mg} \mathrm{L}^{-1}\right)$ : $\mathrm{B}(0.5), \mathrm{Cu}(0.1)$, Fe-EDDHMA (1.8), Mn (0.4), Mo (0.06) and $\mathrm{Zn}(0.2)$. The nutrient solution used for fertigation initially had an electrical conductivity (EC) of $2.0 \mathrm{dS} \mathrm{m}^{-1}$, which was maintained in all treatments. At $31 \mathrm{DAT}$, the composition of fertigation solution changed resulting in an EC of $1.5 \mathrm{dS} \mathrm{m}^{-1}$. The EC value was $1.83 \mathrm{dS} \mathrm{m}^{-1}$ in the percolate volume from the lysimeters for both irrigation frequencies; and varied between 1.63 and $1.95 \mathrm{dS} \mathrm{m}^{-1}$ when considering the different substrate volumes. Plants were subjected to fertigation until the last harvest, made at 154 DAT.

Three tomato plant samples were taken for vegetative growth evaluation: at $36 \mathrm{DAT}$ (fast growth phase), $68 \mathrm{DAT}$ (maximum growth phase) and $112 \mathrm{DAT}$ (fruit ripening phase). Each sampling consisted of three plants having their leaf area (LA), leaf area index (LAI) and shoot dry matter $(\mathrm{SDM})$ evaluated. Leaf area was determined using a digital planimeter model LI-3100 (Licor, NE, USA), and the leaf area index was estimated by the quotient between leaf area

Table 1 - Composition of concentrated nutrient solution used to prepare the fertigation.

\begin{tabular}{lcc}
\hline Concentrated solutions & Vegetative phase & Fruiting phase \\
\hline A solution (250 L) & $15.0 \mathrm{~kg}$ & $15.0 \mathrm{~kg}$ \\
Ca-nitrate & $2.0 \mathrm{~L}$ & $2.0 \mathrm{~L}$ \\
Micronutrient solution (10X) & $0.6 \mathrm{~kg}$ & $0.6 \mathrm{~kg}$ \\
Fe-chelate (6\%) & & \\
\hline B solution (250 L) & $9.0 \mathrm{~kg}$ & $9.0 \mathrm{~kg}$ \\
Potassium nitrate & $4.0 \mathrm{~kg}$ & $2.0 \mathrm{~kg}$ \\
Monophosphate ammoniun & 0 & $3.0 \mathrm{~kg}$ \\
Monophosphate potassium & $8.0 \mathrm{~kg}$ & $8.0 \mathrm{~kg}$ \\
Mg-sulfate & 0 & $3.0 \mathrm{~kg}$ \\
K-sulfate & & \\
\hline Micronutrient solution (10 L) $10 \mathrm{X}$ & $300 \mathrm{~g}$ & $300 \mathrm{~g}$ \\
Boric acid & $50 \mathrm{~g}$ & $50 \mathrm{~g}$ \\
Copper sulfate & $200 \mathrm{~g}$ & $200 \mathrm{~g}$ \\
Manganese sulfate & $75 \mathrm{~g}$ & $75 \mathrm{~g}$ \\
Zinc sulfate & $15 \mathrm{~g}$ & $15 \mathrm{~g}$ \\
\hline Sodium molibdate & & \\
\hline
\end{tabular}


per plant and the spacing area per plant $\left(0.48 \mathrm{~m}^{2}\right)$. For shoot dry matter determination, plants were dried in a forced air oven at $70^{\circ} \mathrm{C}$ until constant weight.

Leaf gas exchange was evaluated at $142 \mathrm{DAT}$, using an infrared gas analyzer model Li-6400 (Licor, NE, USA). Measures of stomatal conductance (gs), leaf $\mathrm{CO}_{2}$ assimilation (A) and transpiration $(\mathrm{E})$ were taken in the central leaflet of completely expanded leaves exposed to solar radiation, at $10 \mathrm{~h} 00$, $13 \mathrm{~h} 30$ and 16h00, after $142 \mathrm{DAT}$. Measurements were taken under greenhouse conditions of air temperature (between 41.3 and $34.3^{\circ} \mathrm{C}$ ) and humidity (between 33.9 and 20.4\%) and photosynthetic photon flux density, varying between 1170 and $294 \mu \mathrm{mol} \mathrm{m}^{-2} \mathrm{~s}^{-1}$. Mean values of gs are shown at the moment of higher atmospheric demand, i.e., 13h30. A and $\mathrm{E}$ values were integrated for the period between $10 \mathrm{~h} 00$

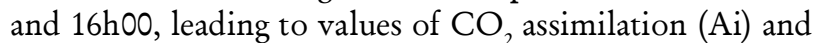
transpiration (Ei) over a $6 \mathrm{~h}$ period. Water use efficiency (WUEi) was calculated by the Ai/Ei ratio, as also made by Silva et al. (2005) and Ribeiro et al. (2009).

Fruit yield and its components were evaluated in eight plants from the central plot rows. Tomatoes were harvested at the reddish fruit stage, starting in August 18 and ending in October 26, 2005 (a total of eight harvests). Tomato bunches were evaluated for fruit number and weight and the total yield was expressed in $\mathrm{kg}$ per plant. The number of tomatoes with blossom-end rot were registered and fruit quality was evaluated by the total soluble solid content (TSS), using a portable refractometer (model RM-M3, Enequipa, SP, Brazil). Twenty tomatoes per plot were collected for quality evaluation at 93, 98, 105, 127 and 134 DAT.

Data were submitted to analyses of variance and mean values were compared by the Duncan test $(p<0.05)$ when the $\mathrm{F}$ test was significant for treatments (substrate volumes and drip irrigation frequencies).

\section{Results and discussion}

No differences in tomato shoot dry matter (SDM) at 36 and 68 DAT were observed when varying substrate volumes (Table 2). However, high drip irrigation frequency enhanced plant growth during the early development phase, increasing SDM around $27 \%$ (Table 2). Interaction between substrate volume and irrigation frequency was obtained for SDM at $112 \mathrm{DAT}$, at the fruit ripening phase. Higher drip irrigation frequency caused increases of $87 \%$ and $54 \%$ in plant SDM when cultivated with 5.0 and $7.5 \mathrm{~L}$ of substrate, respectively (Table 3). Plants grown with $10 \mathrm{~L}$ of substrate were not affected by irrigation frequency. According to these results, one may find a greater effect of the irrigation frequency on biomass yield when plants are grown in smaller substrate volumes. With once-a-day irrigation, tomato plants grown with $10 \mathrm{~L}$ of substrate volume produced higher SDM than those grown with $5 \mathrm{~L}$ of substrate.

For LAI, no interactions between substrate volume and irrigation frequency were observed, regardless of the sampling date. At the $1^{\text {st }}$ evaluation (36 DAT), there was no effect of substrate volume on LAI; in the $2^{\text {nd }}$ evaluation, an increase of $20 \%$ in LAI was noticed in plants grown with 7.5 and 10.0 $\mathrm{L}$ compared to the $5 \mathrm{~L}$ substrate volume (Table 4). In gen-
Table 2 - Ikram tomato shoot dry matter as affected by substrate volume and irrigation frequency, at 36 and 68 days after seedling transplanting (DAT).

\begin{tabular}{ccc}
\hline \multirow{2}{*}{ Treatment } & \multicolumn{2}{c}{ Shoot dry matter } \\
\cline { 2 - 3 } & 36 DAT & 68 DAT \\
\hline Substrate volume (L) & & \\
5.0 & $45.3 \mathrm{a}$ & $158.7 \mathrm{a}$ \\
7.5 & $44.5 \mathrm{a}$ & $186.2 \mathrm{a}$ \\
10.0 & $49.1 \mathrm{a}$ & $181.3 \mathrm{a}$ \\
\hline Irrigation frequency & & \\
\hline Once a day & $40.8 \mathrm{~b}$ & $162.7 \mathrm{a}$ \\
\hline Five times a day & $51.8 \mathrm{a}$ & $188.1 \mathrm{a}$ \\
\hline CV (\%) & 12.7 & 15.1 \\
\hline
\end{tabular}

*For each cause of variation, means followed by the same letters in the column do not differ (Duncan test, $p<0.05$ ).

Table 3 - Ikram tomato shoot dry matter variation depending on the substrate volume and irrigation frequency, at 112 days after seedling transplanting.

\begin{tabular}{lccc}
\hline \multirow{2}{*}{ Irrigation frequency } & \multicolumn{3}{c}{ Shoot dry matter } \\
\cline { 2 - 4 } & \multicolumn{3}{c}{ Substrate volume (L)* } \\
\cline { 2 - 4 } & \multicolumn{3}{c}{ g per plant } \\
\hline Once a day & $248.5 \mathrm{Bb}$ & $289.8 \mathrm{Bab}$ & $344.9 \mathrm{Aa}$ \\
Five times a day & $466.0 \mathrm{Aa}$ & $446.7 \mathrm{Aa}$ & $398.0 \mathrm{Aa}$ \\
\hline
\end{tabular}

*Means followed by the same capital letters in the column and small letters in the row do not differ (Duncan test, $p<0.05$ ). CV $(\%)=13.5$

Table 4 - Leaf area index (LAI) of Ikram tomato plants as affected by substrate volume and irrigation frequency, at 36, 68 and 112 days after seedling transplanting (DAT).

\begin{tabular}{cccc}
\hline \multirow{2}{*}{ Treatment } & \multicolumn{3}{c}{ LAI * } \\
\cline { 2 - 4 } & 36 DAT & $68 \mathrm{DAT}$ & $112 \mathrm{DAT}$ \\
\hline Substrate volume (L) & $-------------\mathrm{m}^{2} \mathrm{~m}^{-2}------------$ \\
5.0 & $1.32 \mathrm{a}$ & $2.64 \mathrm{~b}$ & $2.80 \mathrm{ab}$ \\
7.5 & $1.27 \mathrm{a}$ & $3.19 \mathrm{a}$ & $2.46 \mathrm{~b}$ \\
10.0 & $1.47 \mathrm{a}$ & $3.25 \mathrm{a}$ & $3.15 \mathrm{a}$ \\
\hline Irrigation frequency & & & \\
Once a day & $1.14 \mathrm{~b}$ & $2.39 \mathrm{~b}$ & $2.03 \mathrm{~b}$ \\
Five times a day & $1.57 \mathrm{a}$ & $3.66 \mathrm{a}$ & $3.58 \mathrm{a}$ \\
\hline CV (\%) & 11.8 & 11.7 & 12.3 \\
\hline
\end{tabular}

*For each cause of variation, means followed by the same letters in the column do not differ (Duncan test, $p<0.05$ ).

eral, higher irrigation frequency increased LAI during the plant cycle (Table 4), being such response similar to the one found in shoot dry matter (Tables 2 and 3). LAI results indicated good plant growth and are in agreement with the 
values reported by Pires et al. (2009) and Andriolo et al. (2003). Harmanto et al. (2005) and Pires et al. (2009) reported higher LAI values than those observed in the present study, which might be due to the old leaf removal procedure to keep plants clean and avoid the incidence of diseases. Besides, Harmanto et al. (2005) did not observe any positive effect of different irrigation frequencies (once or thrice a day) on the LAI of plants grown in soils with high organic matter content, which have different water retentions as compared to coconut fiber.

The irrigation frequency of five times a day increased gs during the warmest period of the day (Figure 1). The highest gs values were observed in plants grown with $5 \mathrm{~L}$ and $7.5 \mathrm{~L}$ of coconut fiber substrate, which presented twice the stomatal opening when compared to the other plants. High gs values favored $\mathrm{CO}_{2}$ assimilation and plants showed higher daily carbon gain (Figure 2a). On the other hand, higher stomatal opening also caused higher transpiration, mainly in plants grown with $5 \mathrm{~L}$ of substrate (Figure $2 \mathrm{~b}$ ), meaning higher water consumption. Because responses of $\mathrm{CO}_{2}$ assimilation and transpiration to changes in substrate volume and irrigation frequency were not similar, changes were found in water use efficiency (Figure 2c). The highest WUEi values were noticed in plants growing in $7.5 \mathrm{~L}$ of substrate and subjected to high irrigation frequency, being around 1.6 times higher than WUEi of plants growing in $5.0 \mathrm{~L}$ of substrate and the same irrigation frequency.

The substrate volume did not affect the number of fruits and bunches, and total yield of Ikram tomatoes (Table 5). Nevertheless, better final fruit quality, given by the incidence of blossom-end rot, was obtained when plants were grown with larger substrate volume. High irrigation frequency caused an increase of $54 \%$ on fruit number, $47 \%$ on fruit bunch number and $124 \%$ on fruit yield (Table 5). Regarding fruit quality, once-a-day irrigation probably disfavored calcium assimilation and/or distribution, evidenced by a higher blossom-end rot incidence in tomatoes. Such results were also found by Pires et al. (2009), who reported higher incidence of calcium deficiency in Sahel tomatoes without differences in fruit yield when plants were grown with once or five irrigations per day.

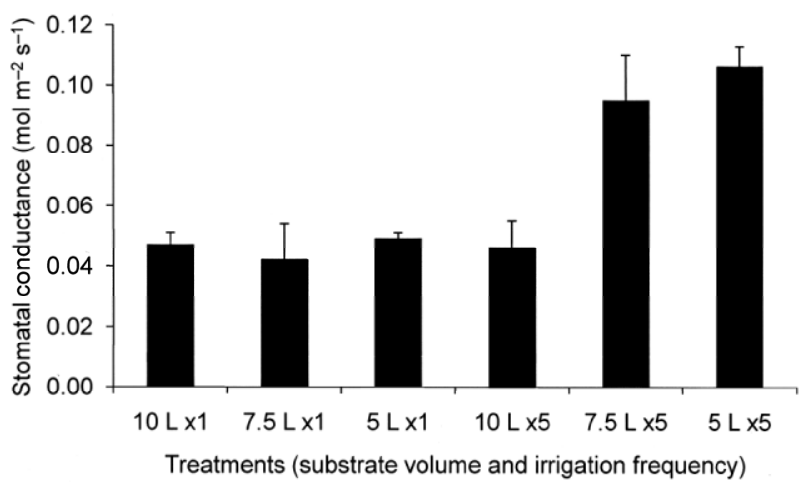

Figure 1 - Stomatal conductance of tomato plants subjected to variation of substrate volume and irrigation frequency under greenhouse conditions. Each bar is the mean value of four replications ( \pm standard error).
Regardless of irrigation frequency, higher plant growth and development were observed with the larger substrate volume (Tables 3 and 4); however, no differences in fruit yield were noticed among the three substrate volumes (Table 5). Higher occurrence of blossom-end rot in plants grown with $5 \mathrm{~L}$ compared to $10 \mathrm{~L}$ of substrate (Table 5) indicates that tomato plants grown in smaller volumes of substrate require a particular adjustment of the irrigation management.

Positive effects of higher irrigation frequency were observed for SDM (Tables 2 and 3), LAI (Table 4), fruit yield and its components (Table 5), such an irrigation management being recommended for similar growing conditions. In fact, high frequency irrigation is possible and usual when growing crops under greenhouse conditions, where automated irrigation systems are commonly found. As a better plant development provided positive effects on Ikram tomato yield,
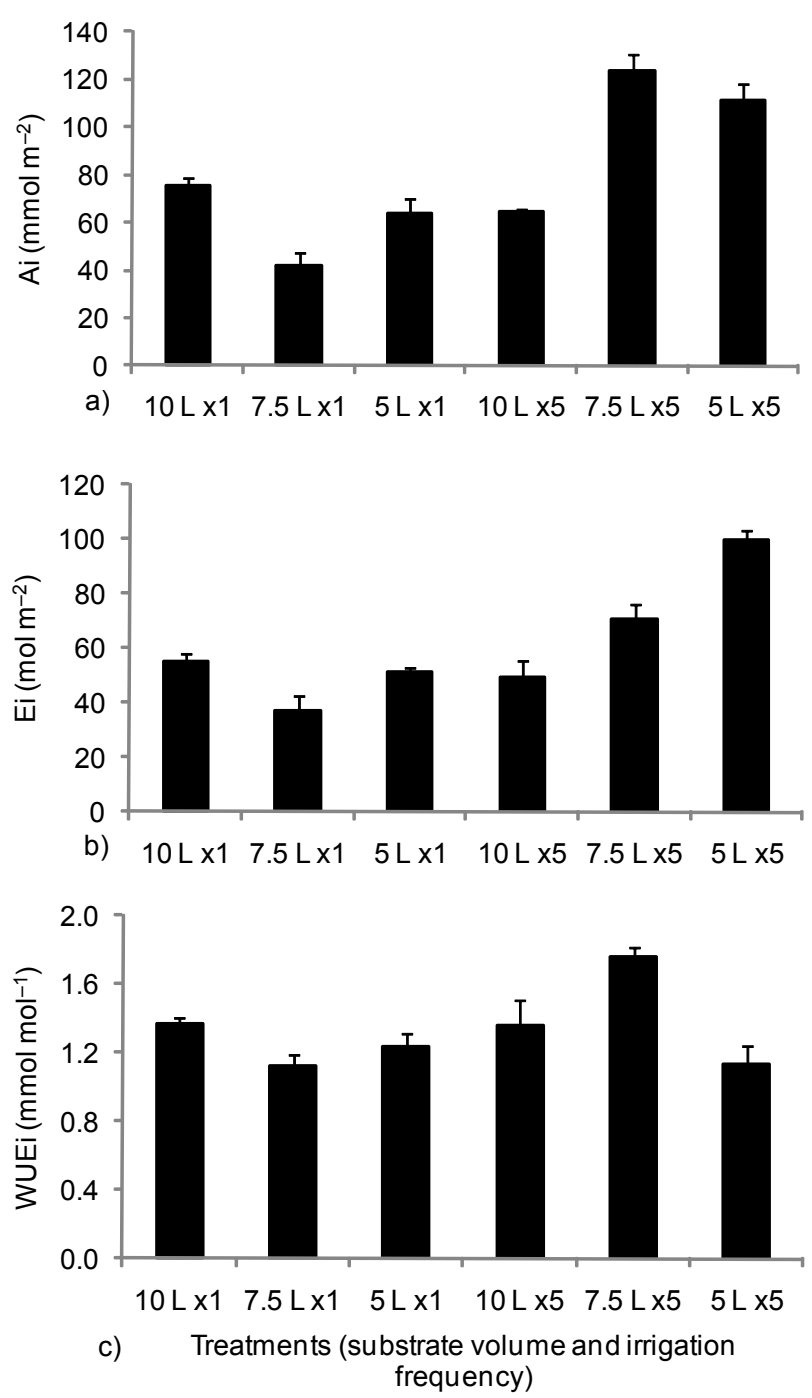

Figure 2 - Diurnal-integrated $\mathrm{CO}_{2}$ assimilation ( $\mathrm{Ai}$, in a), transpiration (Ei, in b) and water use efficiency (WUEi, in c) of tomato plants subjected to variation of substrate volume $(10,7.5$ and $5 \mathrm{~L})$ and irrigation frequency (one or five times per day) under greenhouse conditions. Each bar is the mean value of four replications ( \pm standard error). 
Table 5 - Number of fruits, fruit bunches, fruit with blossom-end rot, total fruit yield, fruit soluble solid contents (TSS) of Ikram tomatoes, as affected by substrate volume and irrigation frequency.

\begin{tabular}{llcccc}
\hline Treatment & Fruit & Bunches & Fruit with blossom-end rot & Fruit yield & TSS \\
\hline & --0.0 & kg per plant & Brix \\
\hline 5.0 & $67.29 \mathrm{a}$ & $11.85 \mathrm{a}$ & $6.56 \mathrm{a}$ & $5.13 \mathrm{a}$ & $6.85 \mathrm{a}$ \\
7.5 & $67.50 \mathrm{a}$ & $11.94 \mathrm{a}$ & $4.33 \mathrm{~b}$ & $5.54 \mathrm{a}$ & $6.59 \mathrm{a}$ \\
10.0 & $63.96 \mathrm{a}$ & $11.67 \mathrm{a}$ & $3.52 \mathrm{~b}$ & $5.71 \mathrm{a}$ & $6.68 \mathrm{a}$ \\
Irrigation frequency & & & & & \\
Once a day & $52.29 \mathrm{~b}$ & $9.58 \mathrm{~b}$ & $6.10 \mathrm{a}$ & $3.38 \mathrm{~b}$ & $7.49 \mathrm{a}$ \\
Five times a day & $80.42 \mathrm{a}$ & $14.04 \mathrm{a}$ & $3.50 \mathrm{~b}$ & $7.56 \mathrm{a}$ & $5.93 \mathrm{~b}$ \\
\hline CV (\%) & 10.1 & 10.0 & 38.9 & 10.9 & 6.4 \\
\hline
\end{tabular}

"For each cause of variation, means followed by the same letters in the column do not differ (Duncan test, $p<0.05$ ).

we may argue that high irrigation frequency associated with a smaller substrate volume might affect photoassimilate partitioning between shoot and root. As a consequence, high irrigation frequency would enhance SDM, which was found in plants grown with $5 \mathrm{~L}$ and $7.5 \mathrm{~L}$ substrate volume (Table 3). As an integrated response, plants did not need to increase the root system due to the prompt availabilities of water and nutrients in the smaller substrate volume.

The higher plant hydration during the warmest hours is suggested to be a result of the greater stomatal opening (Figure 1). Thus, higher $\mathrm{CO}_{2}$ assimilation and water transpiration occurred in plants submitted to five daily irrigations and cultivated with $5 \mathrm{~L}$ and $7.5 \mathrm{~L}$ of substrate (Figure 2). Apparently, higher $\mathrm{CO}_{2}$ assimilation should lead to increments in plant biomass and enhance tomato yield. Nevertheless, one should also consider that increases in tomato yield are consequences not only of higher carbon uptake during the maturation phase. In fact, high fruit yield is a final result of increases in $\mathrm{CO}_{2}$ uptake during the entire plant cycle. Another important question is the leaf area, which increased with high irrigation frequency (Table 4). According to this data, we may suppose that the overall plant photosynthesis $(\mathrm{LA} \times \mathrm{Ai})$ also increased, leading to higher SDM in plants subjected to high irrigation frequency.

The positive effects of high irrigation frequency were not always observed. Harmanto et al. (2005) did not observe any effect of once or thrice a day irrigation frequency on cherry tomato production (Troy 489 hybrid). On the other hand, Ismail et al. (2008) observed increases in tomato yield with higher daily irrigation frequency compared to once-a-day irrigation when plants were grown in soil conditions. Besides genotypic variation, one should consider variations caused by different growth media, another important issue when comparing studies. It is known that the soil or substrate characteristics such as water retention influence water management of potted plants (Sezen et al., 2010).

An adequate water management should have as aim high fruit yield and quality with high water use efficiency. This performance was obtained by plants grown with $7.5 \mathrm{~L}$ of substrate volume and five-a-day irrigation frequency, as shown in Tables 2 to 5 and Figures 1 and 2. When compared to a single daily irrigation, an increase of 2.24 times in fruit yield and reduction (almost half) in incidence of blossom-end rot were obtained when plants were irrigated five times per day. Conversely, one daily application increased total soluble solids of tomatoes, which was probably caused by the small number of tomatoes and bunches and also low fruit yield (Table 5). Although high irrigation frequency have reduced total soluble solids of tomatoes (- $21 \%)$, we may suggest that fruit quality, given by fruit health, was favored when plants received five irrigations per day. Accordingly, Abbott et al. (1986) also observed that four irrigations per day favored tomato quality when compared to one irrigation per day.

There is little information about cluster-type tomato production under protected cultivation and soilless media. Despite the higher economic value of the tomato fruit, the production system is more expensive and should be maximized to reduce losses of resources such as substrate and increase nutrient use efficiency. The possibility of using drip fertigation permanently installed in the crop system with smaller substrate volumes offers perspectives of lowering the production costs.

\section{References}

Abbott, J.D.; Peet, M.M.; Willits, D.H.; Sanders D.C.; Gough, R.E. 1986. Effects of irrigation frequency and scheduling on fruit production and radial fruit cracking in greenhouse tomatoes in soil beds and in a soil-less medium in bags. Scientia Horticulturae 28: 209-219.

Andriolo, J.L.; Witter, M.; Dal Ross, T.; Godói, R.S. 2003. Growth and development of tomato plants in substrate with re-use of drained nutrient solution. Horticultura Brasileira 21: 485-489. (in Portuguese, with abstract in English).

Berjón, M.A.; Murray, P.N.; Benedito, C.C. 2005. Substrates for soilless culture and fertigation. p.299-354. In: Cadahía, C., ed. Fertigation: vegetable crops, fruit and ornamental. Mundi-Prensa, Madrid, Spain. (in Spanish).

Carrijo, O.A.; Vidal, M.C.; Reis, N.V.B.; Souza, R.B.; Makishima, N. 2004. Tomato crop production under different substrates and greenhouse models. Horticultura Brasileira 22: 5-9. (in Portuguese, with abstract in English).

Castilla, N.; Montalvo, T. 2005. Irrigation scheduling. p.277-298. In: Cadahía, C., ed. Fertigation: horticultural crops, fruit trees and ornamental. Mundi-Prensa, Madrid, Spain. (in Spanish).

Çelikel, G. 1999. Effect of different substrates on yield and quality of tomato. Acta Horticulturae 491: 353-356. 
Chen Lopez, J.C.; Waller, P.; Giacomelli, G.; Tuller, M. 2008. Physical characterization of greenhouse substrates for automated irrigation management. Acta Horticulturae 797: 333-338.

Fandi, M.; Al-Muhtaseb, J.A.; Hussein, M.A. 2008. Yield and fruit quality of tomato as affected by the substrate in an open soilless culture. Jordan Journal of Agricultural Sciences 4: 65-72.

Harmanto, V.M.; Salokhe, M.S.; Babel, M.S.; Tantau, H.J. 2005. Water requirement of drip irrigated tomatoes grown in greenhouse in tropical environment. Agricultural Water Management 71: 225242.

Ismail, S.M.; Ozawa, K.; Khondaker, N.A. 2008. Influence of single and multiple water application timings on yield and water use efficiency in tomato (variety First power). Agricultural Water Management 95: 116-122.

Mahajan, G.; Singh, K.G. 2006. Response of greenhouse tomato to irrigation and fertigation. Agricultural Water Management 84: 202206.

Pires, R.C.M.; Furlani, P.R.; Sakai, E.; Lourenção, A.L.; Silva, E.A.; Torre Neto, A.; Melo, A.M.T. 2009. Tomato development and yield under different irrigation frequencies in greenhouse. Horticultura Brasileira 27: 228-234. (in Portuguese, with abstract in English).

Ribeiro, R.V.; Machado, E.C.; Santos, M.G.; Oliveira, R.F. 2009. Photosynthesis and water relations of well-watered orange plants as affected by winter and summer conditions. Photosynthetica 47: 215-222.

Sampaio, R.A.; Ramos, S.J.; Guilherme, D.O.; Costa, C.A.; Fernandes, L.A. 2008. Tomato seedlings production using substrates with coconut fiber and rock waste. Horticultura Brasileira 26: 499-503. (in Portuguese, with abstract in English).
Sánches, F.P. 1999. Properties and characteristics of the substrates: peat and coir. p. 65-92. In: Fernández, M.F.; Gómez, I.M.C., eds. Soilless cultivation. II. Specialization Course. Dirección General de Investigación y Formación Agraria de la Junta de Andalucía, Almería, Spain. (in Spanish).

Sezen, S.M.; Celikel, G.; Yazar, A.; Mendi, Y.Y.; Sahinler, S.; Tekin, S.; Gencel, B. 2006. Effects of drip irrigation management and different soilless culture on yield and quality of tomato grown in a plastic house. Pakistan Journal of Biological Sciences 9: 766-771.

Sezen, S.M., Celikel, G., Yazar, A., Tekin, S., Kapur, B., 2010. Effect of irrigation management on yield and quality of tomatoes grown in different soilless media in a glasshouse. Scientific Research and Essay 5: 41-48.

Silva, C.R.; Folegatti, M.V.; Silva, T.J.A.; Alves Júnior, J.; Souza, C.F.; Ribeiro, R.V. 2005. Water relations and photosynthesis as criteria for adequate irrigation management in "Tahiti" lime trees. Scientia Agricola 62: 415-422.

Sonneveld, C; Straver, N. 1994. Nutrient solutions for vegetables and flowers grown on water or substrates. Proefstation voor Tuinbouw onder Glas Te Naaldwijk, Wagenningen, Netherlands. (Series: Voedingsoplossingen Glastuinbouw, 8)

Received April 05, 2010

Accepted October 04, 2010 